\title{
MATRIK
}

Jurnal Manajemen dan Teknik Industri-Produksi

Journal homepage: http://www.journal.umg.ac.id/index.php/matriks

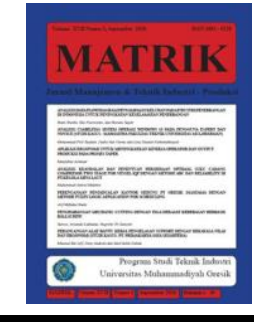

\section{Upaya Meningkatkan Kualitas Produk Bumbu Tabur Balado Pada Proses Mixing Menggunakan Metode PDCA Studi Kasus Di PT. ABCD}

\author{
Meri Prasetyawati ${ }^{*}$, Leola Dewiyani ${ }^{2}$, Umi Marfuah $^{3}$, Casban $^{4}$, Sholahudin Latif $^{5}$ \\ Jurusan Teknik Industri, Fakultas Teknik, Universitas Muhammadiyah Jakarta \\ Jl. Cempaka Putih Tengah 27 Jakarta Pusat, Jawa Barat, Indonesia \\ meri.prasetyawati@ftumj.ac.id
}

\begin{tabular}{l} 
INFO ARTIKEL \\
\hline Jejak Artikel : \\
1O November 2020 \\
Revisi dari reviewer \\
23 Februari 2021 \\
Publish \\
30 Maret 2021 \\
\end{tabular}

\section{Kata Kunci :}

Reject menggumpal, Mixing, Balado, PDCA
ABSTRAK

PT ABCD terletak di Tangerang, merupakan sebuah perusahaan pengolahan pangan di bidang bumbu. Dengan varian bumbu tabur, bahan baku dan tepung krispi. Semakin meningkatnya kapasitas produksi di PT ABCD, maka semakin meningkat pula pengawasan dan pengendalian terhadap kualitas. Bumbu tabur adalah salah produk yang komoditinya tinggi. Varian rasa yang paling dominan adalah Balado, karena permintaan dari konsumen yang paling di minati. Oleh karena itu setiap produksi bumbu tabur balado sering terjadi reject menggumpal dan waktu mixing yang tidak susuai standar. Volume reject menggumpal saat ini lebih dari 1 $\%$ total produksi, dan waktu 80 menit setiap ton. Hal itu yang menjadi masalah perusahaan dikarenakan standar perusahaan untuk volume reject menggumpal kurang dari $1 \%$ total produksi dan waktu yang dibutuhkan 45 menit. Berdasarkan data tersebut menunjukan bahwa tingginya volume reject menggumpal dan waktunya cukup lama. Metode yang digunakan untuk memecahkan masalah tersebut adalah dengan menggunakan metode PDCA (Plan, Do, Check, Action). Melalui kegiatan Quality Control Circle agar diperoleh informasi - informasi dari hasil diskusi yang dapat membantu memecahkan masalah tersebut. Pengumpulan data diperoleh dari dokumen perusahaan. Hasil penelitian ini adalah menurunkan volume reject menggumpal artinya upaya perbaikan yang dilakukan untuk menurunkan volume reject menggumpal dan waktu mixing hingga sesuai dengan standar perusahaan. Setelah perbaikan dilakukan diperoleh hasil bahwa volume reject menggumpal sekarang menjadi $0.96 \%$ sesuai dengan standar perusahaan dan waktu yang dibutuhkan menjadi 45 menit. Walaupun untuk penurunan waktu mixing tidak langsung sesuai dengan yang diharap yang artinya masih ada penyesuaian selama 3 bulan awal yang jauh dari standar perusahaan tetapi mengalami penurunan. 


\section{Pendahuluan}

Industri makanan ringan di Indonesia berkembang sangat pesat. Munculnya berbagai industri makanan ringan di Indonesia memicu terjadinya persaingan antar industri makanan ringan sehingga industri berlomba-lomba memproduksi makanan ringan yang memiliki daya saing lebih baik dibandingkan kompetitornya. PT. ABCD merupakan sebuah perusahaan pengolahan pangan di bidang bumbu tabur. PT. ABCD Berlokasi di Tangerang Selatan dan Pabrik di Pergudangan Cikupa, Tangerang.

Permasalahan yang dihadapi oleh PT. ABCD adalah target produksi bumbu tabur yang tidak tercapai, dikarenakan waktu mixing yang terlalu lama dan banyaknya reject hasil produksi. Proses mixing saat ini membutuhkan waktu $80 \mathrm{menit} /$ ton bumbu tabur, standart yang telah ditetapkan perusahaan adalah 45 menit/ton bumbu tabur. Untuk toleransi reject produksi yaitu kurang dari $1 \%$ dari total produksi yang telah ditetapkan oleh perusahaan.

Berikut adalah tabel yang menunjukan data produksi dan reject bumbu tabur selama bulan Januari 2019 sampai Juni 2019

Tabel 1. Produksi Bumbu Tabur \& reject Bulan Januari - Juni 2019

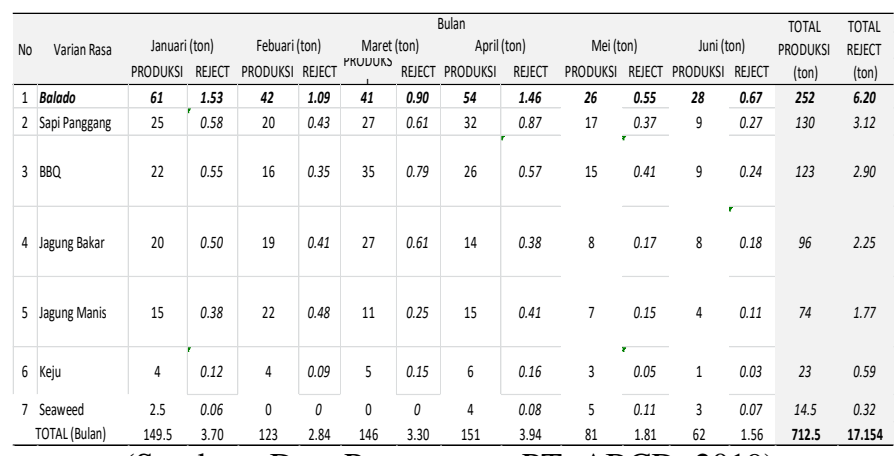

(Sumber : Data Pengamatan PT. ABCD, 2019)

Dapat dilihat dari tabel diatas bahwa varian rasa produk bumbu tabur yang paling banyak adalah rasa balado. Produksi bumbu balado selama Januari - Juni 2019 dengan kuantiti 252 ton, menghasilkan reject sebesar 7,97 ton.
Tabel 2. Kriteria reject Bumbu Tabur Balado Bulan Januari 2019 - Juni 2019

\begin{tabular}{llc|c|c|c|c|c|c}
\hline \multirow{2}{*}{ No } & \multirow{2}{*}{ Kriteria Reject } & \multicolumn{5}{c}{ BULAN (ton) } & & \multirow{2}{*}{ TOTAL } \\
& Januari & Febuari & Maret & April & Mei & Juni & \\
\hline 1 Menggumpal & 1.53 & 1.09 & 0.9 & 1.46 & 0.55 & 0.67 & 6.2 \\
\hline 2 & Warna menyimpang & 0.25 & 0.13 & 0.3 & 0.55 & 0.17 & 0.15 & 1.55 \\
\hline 3 & Rasa dan aroma menyimpang & 0.12 & 0.1 & 0 & 0 & 0 & 0 & 0.22 \\
\hline TOTAL REJECT BALADO PER BULAN & 1.9 & 1.32 & 1.2 & 2.01 & 0.72 & 0.82 & 7.97 \\
\hline
\end{tabular}

(Sumber : Data Pengamatan PT. ABCD, 2019)

Dari data di atas, reject menggumpal terbesar pada bumbu balado disebabkan oleh menggumpalnya produk saat proses produksi, ini sangat menghambat, karena kuantiti dari orderan menjadi berkurang. Proses produksi untuk pembuatan bumbu tabur ialah dengan menimbang komposisi bahan sesuai formulasi, kemudian di masukan ke dalam mesin mixing, kemudian dilakukan proses pencampuran hingga tercampur. Setelah proses tersebut barulah proses penimbangan, lalu dikemas ke dalam kardus.

Setiap proses pencampuran di mesin mixing, antara bahan baku kering dan bahan baku basah / cair tidak tercampur sempurna, dikarenakan bahan baku basah hanya melalui proses penuangan langsung ke dalam mesin mixing saja, sehingga belum tentu tercampur semua, sebagian ada yang menempel di dinding mesin, dan operator harus memastikan bahan baku cair tersebut dengan cara mematikan mesin terlebih dahulu kemudian membuka mesin dan membersihkan area yang menempel dengan scoop stainless. Proses mixing saat ini memakan waktu 80 menit untuk kapasitas produksi 1 ton bumbu tabur. Masalah terbesar ialah ketika proses mixing yang kurang merata sehingga menghasilkan produk yang tidak standart dari segi kenampakan, rasa, dan aroma. Hal tersebut yang menjadi masalah karena tidak sesuai dengan standar perusahaan yaitu waktu mixing 45 menit per ton.

Saat ini proses mixing berjalan lama dikarenakan operator harus membuka tutup mesin mixing untuk mengecek apakah bahan sudah tercampur merata, berakibat pada target jumlah produksi yang tidak tercapai. Kapasitas produksi untuk setiap harinya biasa mencapai 6 sampai dengan 7 ton/hari. Dengan metode proses produksi yang dilakukan saat ini, dirasa belum menghasilkan kapasitas yang maksimal 
setiap harinya. Sangat jelas terlihat bahwasanya metode mixing saat ini jauh lebih besar dari standar perusahaan. Jika dibiarkan hal tersebut bisa menimbulkan kerugian pada perusahaan.

Akibat dari reject menggumpal bumbu tabur balado ini, akan menhambat proses selanjutnya seperti proses ayak dan proses pengemasan. Sehingga waktu mixing bertambah dikarenakan adanya penambahan waktu penanganan bumbu yang menggumpal di mesin mixing. Jadi ketika dalam proses produksi bumbu tabur balado terdapat reject menggumpal, maka secara otomatis waktu mixing juga akan bertambah, tidak sesuai dengan standart perusahaan.

Penggunaan alat dan Teknik kualitas sebagai sarana untuk meningkatkan kualitas dan kinerja perusahaan [1]. Kecacatan dapat disebabkan beberapa faktor yaitu: manusia, lingkungan, material, dan metode. Faktor-faktor penyebab ini dapat terjadi secara bersamaan dan saling mempengaruhi [2]. Dalam kegiatan produksinya, perusahaan selalu berupaya agar menghasilkan produk yang baik dan menekan kerusakan produk [3]. Menentukan penyebab kecacatan dengan menggunakan diagram Pareto dan metode Ishikawa, kemudian mengusulkan perbaikan sistem dengan konsep $5 \mathrm{~W}+1 \mathrm{H}$ [4]. Kualitas merupakan salah satu faktor penting penentu keberhasilan suatu perusahaan dalam menguasai persaingan, melakukan perbaikan sesuai dengan akar permasalahan yang telah ditemukan [5]. Penerapan pengendalian kualitas dengan menggunakan metode atau aktivitas perbaikan kualitas bertujuan untuk mengurangi persentase produk cacat, sehingga produk yang dihasilkan memiliki kualitas yang baik sehingga keuntungan dan kepuasan pelanggan dapat tercapai [6]. Untuk mencapai target kualitas yang diharapkan dan tidak membuat keterlambatan dalam delivery finish unit, kegiatan pengendalian kualitas tersebut dilakukan dengan menggunakan metode dasar pengendalian kualitas (QC 7 Tools) dan siklus Plan - Do - Check - Action (PDCA) [7]. Penulis melakukan pengamatan terhadap proses produksi plastic dan pengujian kualitasnya, sehingga dapat diketahui masalah-masalah yang sering terjadi selama proses produksi maupun masalah yang berkaitan dengan kualitas produk [8]. Proses produksi yang memperhatikan kualitas akan menghasilkan produk yang bebas dari kerusakan. Hal ini dapat menghindarkan pemborosan dan inefisiensi sehingga biaya produksi perunit dapat ditekan dan harga produk menjadi lebih kompetitif [9]. Pengendalian kualitas statistik merupakan teknik penyelesaian masalah yang digunakan untuk memonitor, mengendalikan, menganalisis, mengelola dan memperbaiki produk dan proses menggunakan metodemetode statistik [10]. Metode PDCA adalah kegiatan proses perbaikan berulang untuk memecahkan suatu permasalahan dalam pengendalian kualitas dan termasuk dalam Total Quality Management (TQM) yang mana TQM ini adalah penerapan dari metode kuantitatif dan pengetahuan untuk memperbaiki material dan jasa yang tentunya memperbaiki proses dan upaya untuk memenuhi kepuasan pelanggan [11]. Proses perbaikan menggunakan metode Plan Do Check Action (PDCA) ditemukan bahwa penyebab cacat Insufficient epoxy karena pengontrolan masih manual mengandalkan faktor manusia dan sebagai solusi dari permasalahan tersebut yaitu dengan pemasangan sebuah sensor detektor yang akan mendeteksi epoxy secara otomatis [12]. Proses produksi painting merupakan proses produksi yang kompleks, dimana kecacatan bisa diakibatkan oleh partikel debu atau noda kecil yang tidak terlihat oleh mata, metode PDCA dapat menjadi salah satu metode yang sistematis untuk melakukan aktivitas perbaikan terutama dalam permasalahan kualitas [13]. Berdasarkan hasil penelitian menggunakan metode PDCA di PT Panarub Industry untuk permasalahan yang terdapat pada kualitas sepatu model swift run antara lain adalah faktor manusia yaitu karyawan yang kurang kompeten, faktor material yaitu kualitas bahan baku yang menurun dan tidak menjalankan sistem FIFO pada ruang penyimpanan, faktor mesin yaitu kurangnya penjadwalan dan pengecekan mesin secara berkala sehingga menyebabkan mesin sering mengalami kerusakan [14]. Setelah implementasi perbaikan dilakukan melalui penerapan metode PDCA tingkat kecacatan menurun dari yang sebelumnya adalah 0.085 DPU menjadi 0.030 DPU, hal ini menunjukkan bahwa kualitas strip XX kaplet meningkat dengan penurunan cacat sebanyak 0.055 DPU [15]. Siklus PDCA berguna sebagai pola kerja 
dalam perbaikan suatu proses atau sistem. Bagaimanapun implementasi dari setiap tahap PDCA, mulai dari tahap P (Plan) sampai A (Act) memerlukan seperangkat alat bantu yang dapat digunakan untuk mengefektifkan Tindakan dalam setiap tahapan.

\section{Metode Penelitian}

Metode pengumpulan data yang akan digunakan adalah melakukan pengamatan langsung diperusahaan yang menjadi objek penelitian. Pengumpulan data terdiri dari data produksi, data reject dan waktu mixing produksi bumbu tabur balado.

Setelah data terkumpul selanjutnya diolah, pada pengolahan data disini menggunakan metode PDCA ( Plan, Do, Check, Action ) dan Pada tahap ini pula dilakukan analisa dan dibahas berdasarkan hubungannya dengan rumusan masalah dan tujuan penelitian yang telah ditetapkan sebelumnya

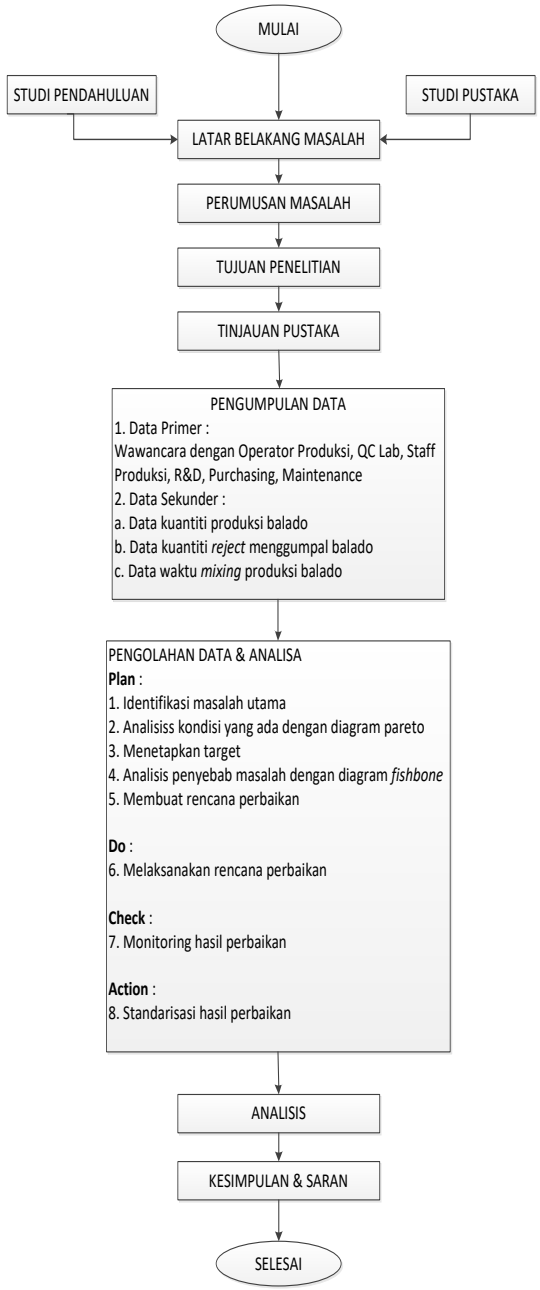

Gambar 1. Flowchart Penelitian

\section{Hasil dan Pembahasan}

\section{A. Perencanaan (Plan)}

Penelitian Pendahuluan

Tabel 3. Data kuantiti produksi, reject menggumpal, waktu mixing produk balado sebelum dilakukan perbaikan periode Januari 2019 - Juni 2019.

\begin{tabular}{|c|c|c|c|c|c|c|c|c|}
\hline \multirow[b]{2}{*}{ № } & \multirow[b]{2}{*}{$\begin{array}{c}\text { BULAN PRODUKSI } \\
\text { BUMBU TABUR } \\
\text { BALADO }\end{array}$} & \multirow[b]{2}{*}{$\begin{array}{c}\text { JUMLAH } \\
\text { PRODUKSI } \\
\text { BALADO (ton) }\end{array}$} & \multicolumn{2}{|c|}{ REEECT PRODUKSI BALADO } & \multicolumn{4}{|c|}{ WAKTU MIXING } \\
\hline & & & $\begin{array}{c}\text { STD REJECT } \\
\text { (kurang dari } 1 \\
\text { \% dari total } \\
\text { produksi) }\end{array}$ & $\begin{array}{c}\text { JUMLAH REJECT } \\
\text { MENGGUMPAL } \\
(\mathrm{kg})\end{array}$ & $\begin{array}{l}\text { STANDART } \\
\text { WAKTU } \\
\text { MIXING PER } \\
\text { TON (menit) }\end{array}$ & $\begin{array}{c}\text { TOTAL } \\
\text { STANDART } \\
\text { WAKTU } \\
\text { MIXING } \\
\text { (menit) }\end{array}$ & $\begin{array}{l}\text { WAKTU } \\
\text { MIXING } \\
\text { SAATINI } \\
\text { (menit) }\end{array}$ & $\begin{array}{r}\text { TOTAL } \\
\text { WAKTU } \\
\text { MIXING } \\
\text { SAATIN } \\
\text { (menit) }\end{array}$ \\
\hline 1 & JANUARI & 61 & 610 & 1530 & 45 & 2745 & 80 & 4880 \\
\hline 2 & FEBUARI & 42 & 420 & 1065 & 45 & 1890 & 80 & 3360 \\
\hline 3 & MARET & 41 & 410 & 900 & 45 & 1845 & 80 & 3280 \\
\hline 4 & APRIL & 54 & 540 & 1460 & 45 & 2430 & 80 & 4320 \\
\hline 5 & MEl & 26 & 260 & 550 & 45 & 1170 & 80 & 2080 \\
\hline 6 & JUNI & 28 & 280 & 695 & 45 & 1260 & 80 & 2240 \\
\hline & TOTAL & 252 & 2520 & 6200 & & 11340 & & 20160 \\
\hline \multicolumn{3}{|c|}{ PERSENTASE REJECT MENGGUMPAL (JAN - JUN 2019) } & \multicolumn{2}{|c|}{$2.46 \%$} & & & & \\
\hline
\end{tabular}

Data diatas periode bulan Januari sampai Juni dapat dilihat bahwa kuanti reject menggumpal cukup tinggi, mencapai 6,2 ton selama 6 bulan dan juga waktu yang diperlukan cukup lama hingga 80 menit per ton. Sedangkan standar perusahaan untuk sebuah proses produksi bumbu tabur adalah reject menggumpal kurang dari $1 \%$ dari total produksi dan waktu mixing selama 45 menit per ton. Ketidaksesuaian tersebut menjadi masalah besar bagi perusahaan.

Menentukan Prioritas Masalah (Breakdown The Problem)

Produk balado menjadi prioritas utama yang harus diselesaikan permasalahannya. Produk ini menjadi masalah besar bagi perusahaan karena merupakan variant rasa yang paling diminati oleh konsumen.

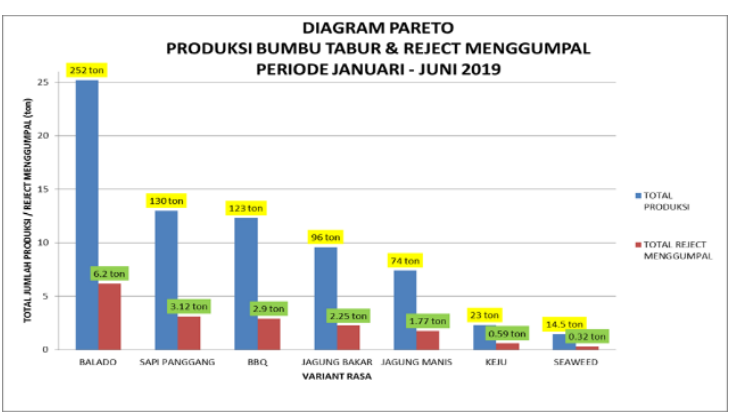

Gambar 2. Diagram Pareto Produksi Bumbu Tabur Periode Januari - Juni 2019 


\section{Menetapkan Target}

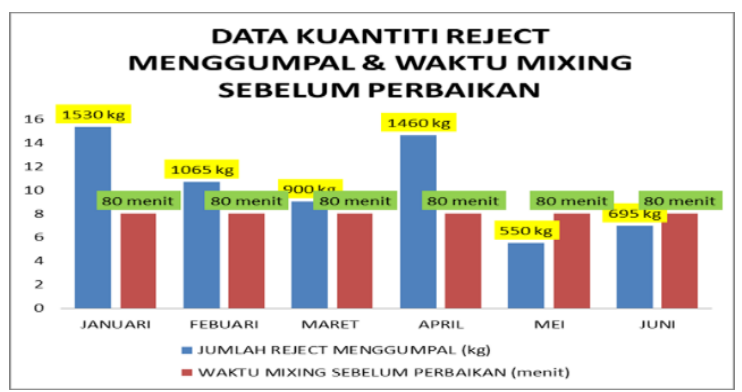

Gambar 3. Data Kuantiti reject Menggumpal \&

Waktu Mixing Sebelum Perbaikan Periode Januari - Juni 2019

Berdasarkan grafik diatas dapat dilihat bahwa reject menggumpal menggumpal dan waktu mixing masih tinggi dan tidak sesuai dengan standart perusahaan.

\section{Menganalisa Penyebab Masalah (Fishbone)}

Setelah diketahui prioritas yang harus dilakukan perbaikan, selanjutnya dibuatkan diagram tulang ikan (fishbone) untuk mencari akar penyebab yang meyebabkan terjadinya masalah tersebut. Diagram ikan (fishbone) diperoleh dari hasil briefing dengan metode brainstorming. Brainstorming digunakan untuk mengetahui apa akar penyebab terjadinya masalah. Brainstorming merupakan cara untuk memacu pemikiran kreatif guna mengumpulkan ide-ide dari suatu kelompok dalam waktu relatif singkat. Brainstorming beranggotakan sepuluh personil dari berbagai departemen diantaranya mgr operasional, mgr produksi, QA, QC, spv produksi, purchasing, R\&D, gudang, maintenance. Brifieng dilakukan pada tanggal 1 Juli 2019 di ruang meeting kantor

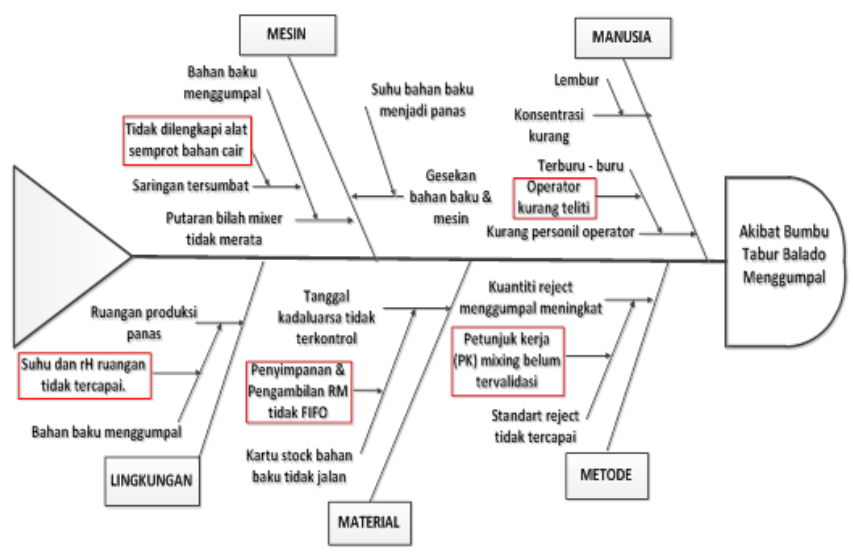

Gambar 4. Diagram Fishbone reject Produksi Bumbu Balado Menggumpal

\section{Membuat Rencana Perbaikan}

Setelah diketahui akar masalah atau penyebab utamanya, kemudian disusunlah langkahlangkah perbaikan.

\section{B. DO}

\section{Implementasi Aktifitas Perbaikan}

Proses mixing sebelum perbaikan dilakukan dengan cara mencampurkan bahan baku kering dan bahan baku cair yang sudah ditimbang sesuai formula di masukan ke dalam mesin mixing secara bersamaan pada satu waktu, Di dalam mesin mixing terdapat bilah-bilah yang berfungsi untuk mencampur semua bahan baku. Akan tetapi pada penerapannya tidak semua bahan tercampur sempurna, ada bahan baku yang menggumpal (blok) turatama bahan baku cair yang tidak tercampur sempurna. Sehingga diperlukan waktu tambahan untuk menghaluskan gumpalan tersebut. Semakin banyak gumpalan yang diperoleh akan menjadi tambahan reject menggumpal produk itu sendiri. Waktu standart untuk mixing kuantiti 1 ton adalah 45 menit. Sedangkan untuk saat ini waktu yaitu 80 menit, kendala utama pada proses pencampuran di mesin mixing yang belum merata menyeluruh.

Perbaikan yang akan dilakukan agar proses mixing tidak menghasilkan kuantiti reject menggumpal cukup banyak dan memakan waktu lama, maka dilakukanlah beberapa proses penunjang aktifitas tersebut.

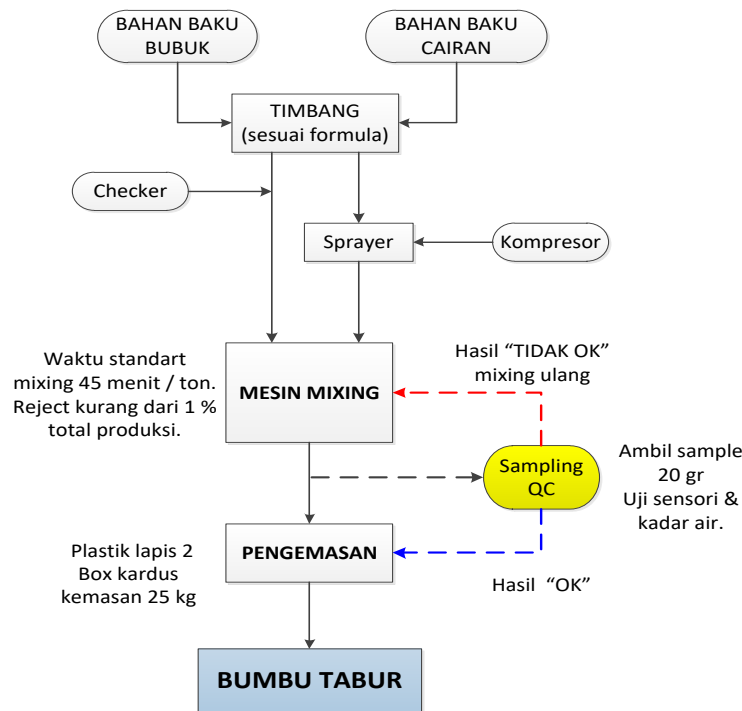

Gambar 5. Flowchart Mixing Produksi Sesudah Perbaikan 
Setelah dilakukan perbaikan, bahwa proses mixing mengalami perubahan yaitu dilakukan dengan cara memisahkan proses pencampuran antara bahan baku bubuk dengan bahan baku cair. Pada bahan baku bubuk setelah proses penimbangan akan di checker ulang untuk validasi timbangan oleh operator timbang, kemudian bahan baku bubuk akan langsung di masukan ke mesin mixing. Sedangkan untuk bahan baku cair, setelah proses timbang kemudian checker untuk validasi, akan dimasukan ke dalam tangki sprayer dengan kapasitas 5 liter cairan. Operator mulai menyalakan panel mesin mixing untuk memcampur bahan baku bubuk terlebih dahulu, kemudian setelah itu operator menyalakan panel sprayer, maka kompresor akan menyala dan memberikan tekanan ke tanki spryer tersebut, dan bahan baku cairan akan mulai disemprotkan dalam bentuk kabut, sehingga lebih cepat homogen.

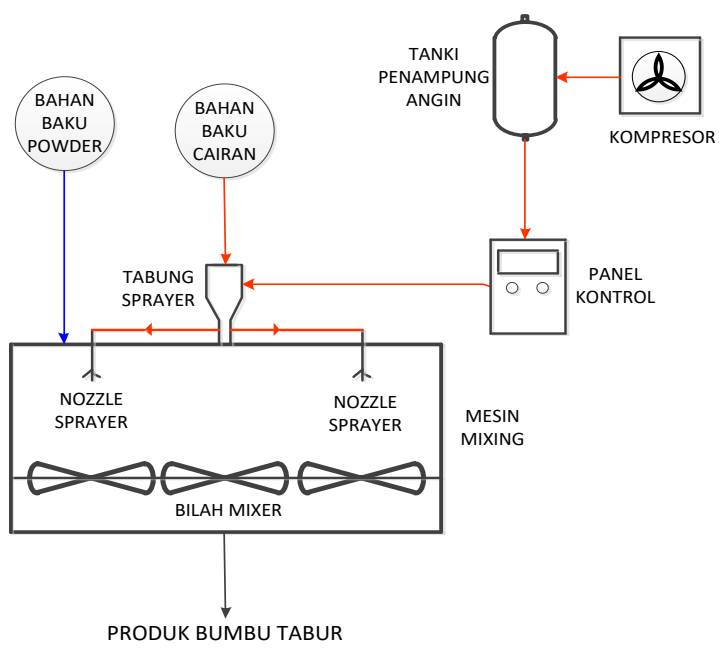

Gambar 6. Proses Flow Diagram Mixing Produksi Sesudah Perbaikan

Perbedaan dari Petunjuk Kerja sebelum dan sesudah perbaikan yaitu terdapat pada penambahan sprayer untuk bahan baku cairan. Selain itu tekanan pada sprayer yang di supply dari kompresor juga harus selalu stabil, agar bahan baku cairan dapat menyebar sempurna dan mendapat hasil yang maksimal.
Tabel 4. Data produksi, reject menggumpal, waktu mixing produk balado sesudah dilakukan perbaikan periode Juli - Des 2019

\begin{tabular}{|c|c|c|c|c|c|c|c|}
\hline \multirow[b]{2}{*}{$\begin{array}{c}\text { BULAN PRODUKSI } \\
\text { BUMBUTABUR } \\
\text { BALADO }\end{array}$} & \multirow[b]{2}{*}{$\begin{array}{c}\text { JUMLAH } \\
\text { PRODUKSI } \\
\text { BALADO (ton) }\end{array}$} & \multicolumn{2}{|c|}{ REIECT PRODUKSI BALADO } & \multicolumn{4}{|c|}{ WAKTUMIXING } \\
\hline & & $\begin{array}{l}\text { STD REEECT } \\
\text { (kurang dari1 } \\
\text { \% daritotal } \\
\text { produksi) }\end{array}$ & $\begin{array}{l}\text { JUMLAH REJECT } \\
\text { MENGGUMPAL } \\
(\mathrm{kg} \mid\end{array}$ & $\begin{array}{l}\text { STANDART } \\
\text { WAKTU } \\
\text { MIXING PER } \\
\text { TON (menit) }\end{array}$ & $\begin{array}{c}\text { TOTAL } \\
\text { STANDART } \\
\text { WAKTU } \\
\text { MIXING } \\
\text { (menit) }\end{array}$ & $\begin{array}{r}\text { WAKTU } \\
\text { MIXING } \\
\text { SAATINI } \\
\text { (menit) }\end{array}$ & $\begin{array}{l}\text { TOTAL } \\
\text { WAKTU } \\
\text { MIXING } \\
\text { SAATIN } \\
\text { (menit) }\end{array}$ \\
\hline 1 JULI & 65 & 650 & 495 & 45 & 2925 & 60 & 3900 \\
\hline 2 AGUSTUS & 59 & 590 & 550 & 45 & 2655 & 70 & 4130 \\
\hline 3 SEPTEMBER & 50 & 500 & 505 & 45 & 2250 & 55 & 2750 \\
\hline 4 OKTOBER & 66 & 660 & 650 & 45 & 2970 & 45 & 2970 \\
\hline 5 NOVEMBER & 46 & 460 & 480 & 45 & 2070 & 45 & 2070 \\
\hline 6 DESEMBER & 41 & 410 & 445 & 45 & 1845 & 45 & 1845 \\
\hline TOTAL & 327 & 3270 & 3125 & & 14715 & & 17665 \\
\hline
\end{tabular}

PERSENTASE REECCT MENGGUMPAL LUUL - DES 2019)

\section{$0.96 \%$}

\section{CHECK}

\section{Evaluasi Aktifitas Perbaikan}

Aktifitas evaluasi dampak dari perbaikan dilakukan pada bulan Juli 2019 - Desember 2019 yang mana semua aktifitas perbaikan sudah selesai dilakukan. Evaluasi dilakukan dengan membandingkan hasil antara sebelum dan sesudah pada proses mixing produksi. Dilihat hasil akhir kuantiti produksi bumbu meningkat dan waktu proses waktu proses mixing juga bertahap menurun sesuai standar perusahaan.

Perhitungan peta kendali $\mathrm{C}$ sebelum revisi

$\bar{C}=\frac{6200}{48}=129,17$

$\bar{s}=115,84$

$\mathrm{UCL} c=129,17+3 \sqrt{115,84}=476,68$

LCL $\mathrm{c}=129,17-3 \sqrt{115,84}=-218,35$

Perhitungan peta kendali $\mathrm{C}$ sesudah revisi $\bar{C}=\frac{3125}{52}=60,10$

$\bar{s}=17,95$

$\mathrm{UCL} \mathrm{c}=60,10+3 \sqrt{17.95}=113,93$

LCL $c=60,10-3 \sqrt{17,95}=6,26$ 


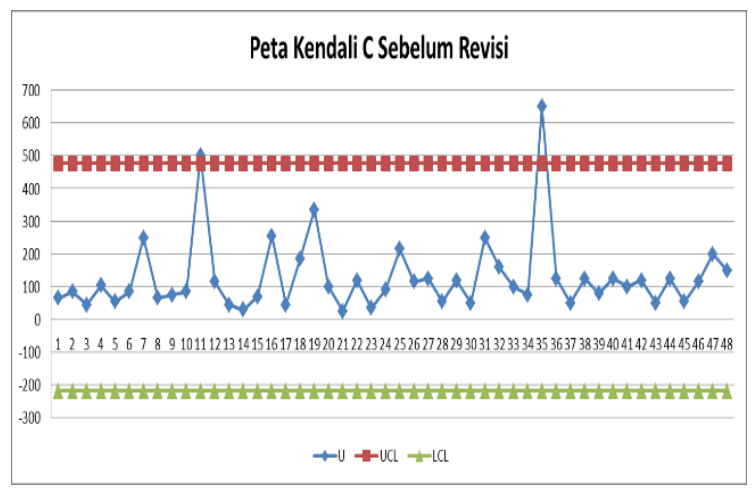

Gambar 7. Peta kendali C sebelum revisi

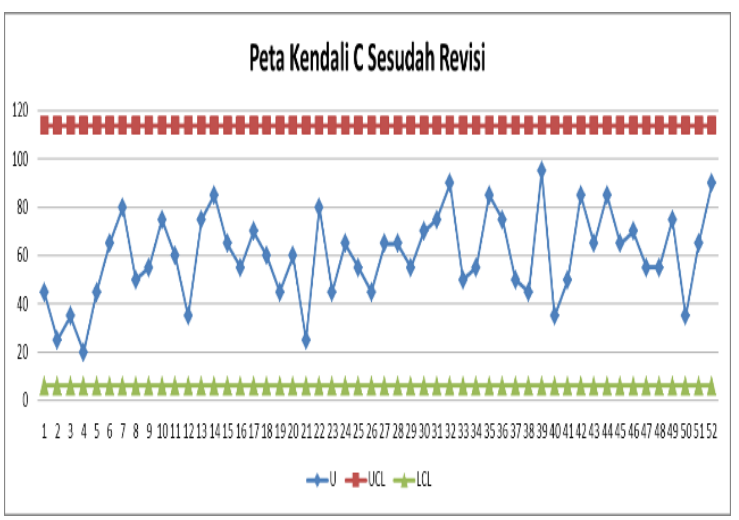

Gambar 8. Peta kendali C sesudah revisi

Tabel 5. Data produksi, reject menggumpal, waktu mixing produk balado sesudah dilakukan perbaikan periode Juli - Desember 2019

\begin{tabular}{|c|c|c|c|c|c|c|c|c|}
\hline \multirow[b]{2}{*}{ № } & \multirow[b]{2}{*}{$\begin{array}{c}\text { BULAN PRODUKSI } \\
\text { BUMBUTABUR } \\
\text { BALADO }\end{array}$} & \multirow[b]{2}{*}{$\begin{array}{c}\text { JUMLAH } \\
\text { PRODUKSI } \\
\text { BALADO (ton) }\end{array}$} & \multicolumn{2}{|c|}{ REJECT PRODUKSI BALADO } & \multicolumn{4}{|c|}{ WAKTU MIXING } \\
\hline & & & $\begin{array}{c}\text { STD REJECT } \\
\text { (kurang dari1 } \\
\text { \% dari total } \\
\text { produksi) }\end{array}$ & $\begin{array}{c}\text { JUMLAH REJECT } \\
\text { MENGGUMMPAL } \\
(\mathrm{kg})\end{array}$ & \begin{tabular}{|} 
STANDART \\
WAKTU \\
MIXING PER \\
TON (menit)
\end{tabular} & $\begin{array}{c}\text { TOTAL } \\
\text { STANDART } \\
\text { WAKTU } \\
\text { MIXING } \\
\text { (menit) }\end{array}$ & $\begin{array}{l}\text { WAKTU } \\
\text { MIXING } \\
\text { SAATINI } \\
\text { (menit) }\end{array}$ & $\begin{array}{r}\text { TOTAL } \\
\text { WAKTU } \\
\text { MIXING } \\
\text { SAATINI } \\
\text { (menit) } \\
\end{array}$ \\
\hline 1 & JULI & 65 & 650 & 495 & 45 & 2925 & 60 & 3900 \\
\hline 2 & AGUSTUS & 59 & 590 & 550 & 45 & 2655 & 70 & 4130 \\
\hline 3 & SEPTEMBER & 50 & 500 & 505 & 45 & 2250 & 55 & 2750 \\
\hline 4 & OKTOBER & 66 & 660 & 650 & 45 & 2970 & 45 & 2970 \\
\hline 5 & NOVEMBER & 46 & 460 & 480 & 45 & 2070 & 45 & 2070 \\
\hline 6 & DESEMBER & 41 & 410 & 445 & 45 & 1845 & 45 & 1845 \\
\hline & TOTAL & 327 & 3270 & 3125 & & 14715 & & 17665 \\
\hline \multicolumn{3}{|c|}{ PERSENTASE REECT MENGGUMPAL (JUL - DES 2019) } & \multicolumn{2}{|c|}{$0.96 \%$} & & & & \\
\hline
\end{tabular}

\section{ACTION}

Standarisasi diperlukan untuk mencegah timbulnya kembali masalah yang sama dikemudian hari dan untuk meningkatkan Petunjuk Kerja (PK) yang sudah ada. Setelah standart ditetapkan, akan dilakukan monitoring pelaksanaannya dan sampai terjadinya perubahan standart kembali.

\section{Kesimpulan dan Saran}

Berdasarkan pengolahan data dan hasil analisis yang telah dilakukan, maka dapat ditarik kesimpulan yaitu upaya penurunan reject menggumpal berhasil sesuai dengan standar perusahaan yaitu sebesar kurang dari $1 \%$ dari total produksi yaitu $\mathbf{0 . 9 6} \%$. Data sebelumnya reject menggumpal mencapai $\mathbf{2 , 4 6} \%$ periode Januari - Juni 2019. Upaya dalam mengurangi waktu mixing, dalam penelitian tidak sesuai harapan, karena terdapat 3 bulan awal tidak standart yaitu bulan Juli - September. Namun tetap ada penurunan dari sebelumnya 80 menit lebih menjadi 45 menit pada bulan Oktober Desember yang sudah mencapai standart.

\section{Saran}

Sebaiknya dilakukan validasi metode Petunjuk Kerja (PK) analisa laboratorium maupun Petunjuk Kerja (PK) Mixing secara berkala. Serta selalu monitoring prosedur mixing.

\section{Daftar Pustaka}

[1] D. I. Prajogo, "PENGGUNAAN TEKNIK DAN ALAT KUALITAS DALAM PROSES PERBAIKAN DAN PENINGKATAN KUALITAS," Jurnal Keilmuan dan Aplikasi Teknik Industri, vol. 2, no. 1, pp. 22 - 27, 2000.

[2] D. W. Farid Wajdi, "PENGUKURAN DAN INTERVENSI PENGENDALIAN KUALITAS PENGELASAN," Jurnal Intech Teknik Industri, vol. 1, no. 1, pp. 15 - 23, 2015.

[3] Sulaeman, "ANALISA PENGENDALIAN KUALITAS UNTUK MENGURANGI PRODUK CACAT SPEEDOMETER MOBIL DENGAN MENGGUNAKAN METODE QCC DI PT INS," Jurnal PASTI, vol. VIII, no. 1, pp. 71 - 95, 2014.

[4] A. Z. A. F. Teguh Yulianto, "PERBAIKAN KUALITAS PRODUK WAJAN DENGAN MENGGUNAKAN 
METODE SIX SIGMA DAN KANO," Jurnal Ilmiah Teknik Industri, vol. 14, no. 2, pp. 167 - 173, 2015.

[5] N. U. H. Arga Adyatama, "PERBAIKAN KUALITAS MENGGUNAKAN PRINSIP KAIZEN DAN 5 WHY ANALYSIS: STUDI KASUS PADA PAINTING SHOP KARAWANG PLANT 1, PT TOYOTA MOTOR MANUFACTURING INDONESIA," Jurnal Teknik Industri, JATI UNDIP, vol. 13, no. 3, pp. 169 - 176, 2018.

[6] R. D. S. Syarifuddin Nasution, "Perbaikan Kualitas Proses Produksi Karton Box Dengan Menggunakan Metode DMAIC Dan Fuzzy FMEA," Jurnal Sistem Teknik Industri, vol. 20, no. 2, pp. 36 - 46, 2018.

[7] F. S. Meri Prasetyawati, "ANALISIS PENGENDALIAN KUALITAS UNTUK MENGURANGI DEFFECT DAN MENINGKATKAN KETEPATAN WAKTU DELIVERY PADA FINISH UNIT DI PT. XYZ," dalam Seminar Nasional Sains dan Teknologi, Jakarta, 2015.

[8] A. S. R. Muhammad Ary Budi Yuwono, "Proses Produksi dan Pengendalian Kualitas Produksi Cat Plastic Coating di PT. Propan Raya ICC," Jurnal PASTI, vol. IX, no. 2, pp. 193-202, 2015.

[9] T. Windarti, "Pengendalian Kualitas Untuk Meminimasi Produk Cacat Pada Proses Produksi Besi Beton,”J@TI UNDIP : Jurnal Teknik Industri, vol. IX, no. 3, pp. 173-180, 2014.

[10] F. W. Vera Defani, "Pengendalian Kualitas Kertas Dengan Menggunakan Statistical Process Controldi Paper Machine3," JITI, vol. 15, no. 2, pp. 8793, 2016.

[11] H. H. A. Cepi Kurniawan, "Penerapan Metode PDCA untuk menurunkan Tingkat Kerusakan Mesin Pada Proses
Produksi Penyalutan," Journal of Industrial Engeering, Scientific Journal on Research and Application of Industrial System, vol. 3, no. 2, pp. 105 106, 2018.

[12] E. S. A. M. Hendra Kurniawan, "Peningkatan Kualitas Produksi Untuk Mengurangi Unit Cacat Insufficient Epoxy Dangan Metode PDCA di Area Die Attach (Studi Kasus Di PT. Unisem)," Profisiensi, vol. 5, no. 1, pp. 44-50, 2017.

[13] H. C. P. Jong Feliando Yonatan, "Upaya Peningkatan Kualitas Part Upper Cover Dengan Metode PDCA di PT Astra Komponen Indonesia," Jurnal Tirta, vol. 3, no. 2, pp. 283-288, 2015

[14] H. P. P. H. Nur Fadilah Fatma, "Penerapan Metode PDCA dalam Peningkatan Kualitas Pada Product Swift Run Di PT. Panarub Industry," Journal Industrial Manufacturing, vol. 5, no. 1, pp. 34-45, 2020.

[15] A. H. D. Santy Utami, "Implementasi Pengendalian Kualitas Produk XX Kaplet Pada Proses Produksi Pengemasan Primer Dengan Penerapan Konsep PDCA," Jurnal Integrasi Sistem Industri, vol. 5, no. 2, pp. 33-42, 2018. 